
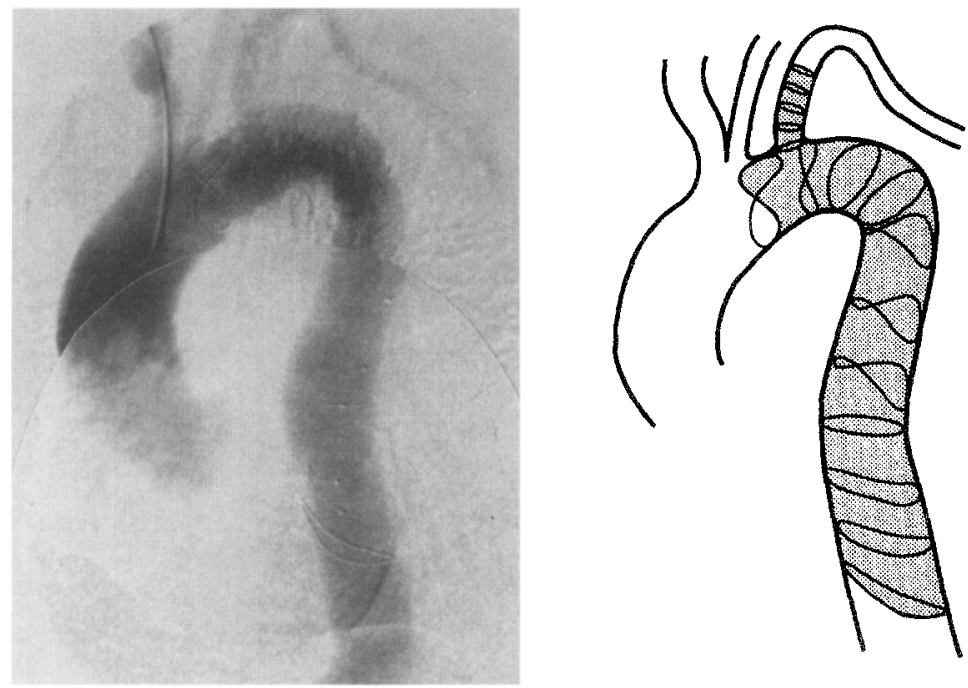

Fig. 2. One month after graft placement, aortography shows good flow of contrast medium through graft, with no leakage into false lumen.

since 1969, when Dotter ${ }^{3}$ initially inserted stainless steel coils as a vascular stent in canine popliteal arteries. Clinical endovascular placement of straight stent grafts for the treatment of aortic dissection has already been reported, ${ }^{4}$ but placement of these stent grafts was limited to sites that did not include the origin of the major aortic arterial branches. With the branched graft, we succeeded in endovascular repair of type B dissection with intimal tear just beyond the left subclavian artery. If long-term results are favorable, endovascular repair of larger dissections in patients with type $B$ dissection would be possible. Careful long-term evaluation and further improvement in devices and techniques will, however, be necessary for extensive clinical use.

\section{REFERENCES}

1. Inoue $\mathrm{K}$, Htay T, Kida M, Fujiwara $\mathrm{H}$. Percutaneous implantation of aortic endovascular graft for created aneurysm: animal experiment [abstract]. Circulation 1991;84(Suppl):n421.

2. Inoue $\mathrm{K}$, Htay $\mathrm{T}$. Long-term follow-up of percutaneously placed aortic endovascular graft: animal experiment [abstract]. Circulation 1992;86(Suppl 1):I636.

3. Dotter CT. Transluminally-placed coilspring endoarterial tube grafts: long-term patency in canine popliteal artery. Invest Radiol 1969;4:329-32.

4. Dake MD, Miller DC, Semba CP, Mitchell RS, Walker PJ, Liddell RP. Transluminal placement of endovascular stentgrafts for the treatment of descending thoracic aortic aneurysms. N Engl J Med 1994;331:1729-34.

\title{
AN ADJUSTABLE, PERCUTANEOUSLY PLACED HELICAL COIL: CONTROL OF LEFT VENTRICULAR FILLING PRESSURE DURING CARDIOPULMONARY BYPASS IN SEVERE LEFT VENTRICULAR FAILURE
}

Theodor Kolobow, MD, Jeffrey Wang, Matteo Giacomini, MD, and Chiara Reali-Forster, MD, Bethesda, Md.

We previously reported that closed-chest total cardiopulmonary bypass through peripheral cannulation can be performed in sheep with induced ventricular fibrillation

From the Pulmonary-Critical Care Medicine Branch, National Heart, Lung, and Blood Institute, National Institutes of Health, Bethesda, Md.

Received for publication Nov. 1, 1995; accepted for publication Feb. 26, 1996.

J Thorac Cardiovase Surg 1996;112:1113-5

Copyright (C 1996 by Mosby-Year Book, Inc.

$0022-5223 / 96 \$ 5.00+0 \quad \mathbf{1 2 / 5 4 / 7 3 1 0 2}$ for at least 3 days, with immediate recovery of normal cardiac and pulmonary function after defibrillation. ${ }^{1}$ Key to the success of this procedure was the development of a percutaneously placed, fixed-size helical coil that is advanced to rest within the lumen of the pulmonary artery valves and the tricuspid valves to keep them open. This allows the retrograde flow of blood from the bronchial venous system and the thebesian venous flow and from the left side of the heart across the lungs (with the heart in ventricular fibrillation), decompressing the left side of the heart. In this article we describe the design and development of a flow-directed, catheter-mounted helical coil system that has an adjustable diameter and is therefore 

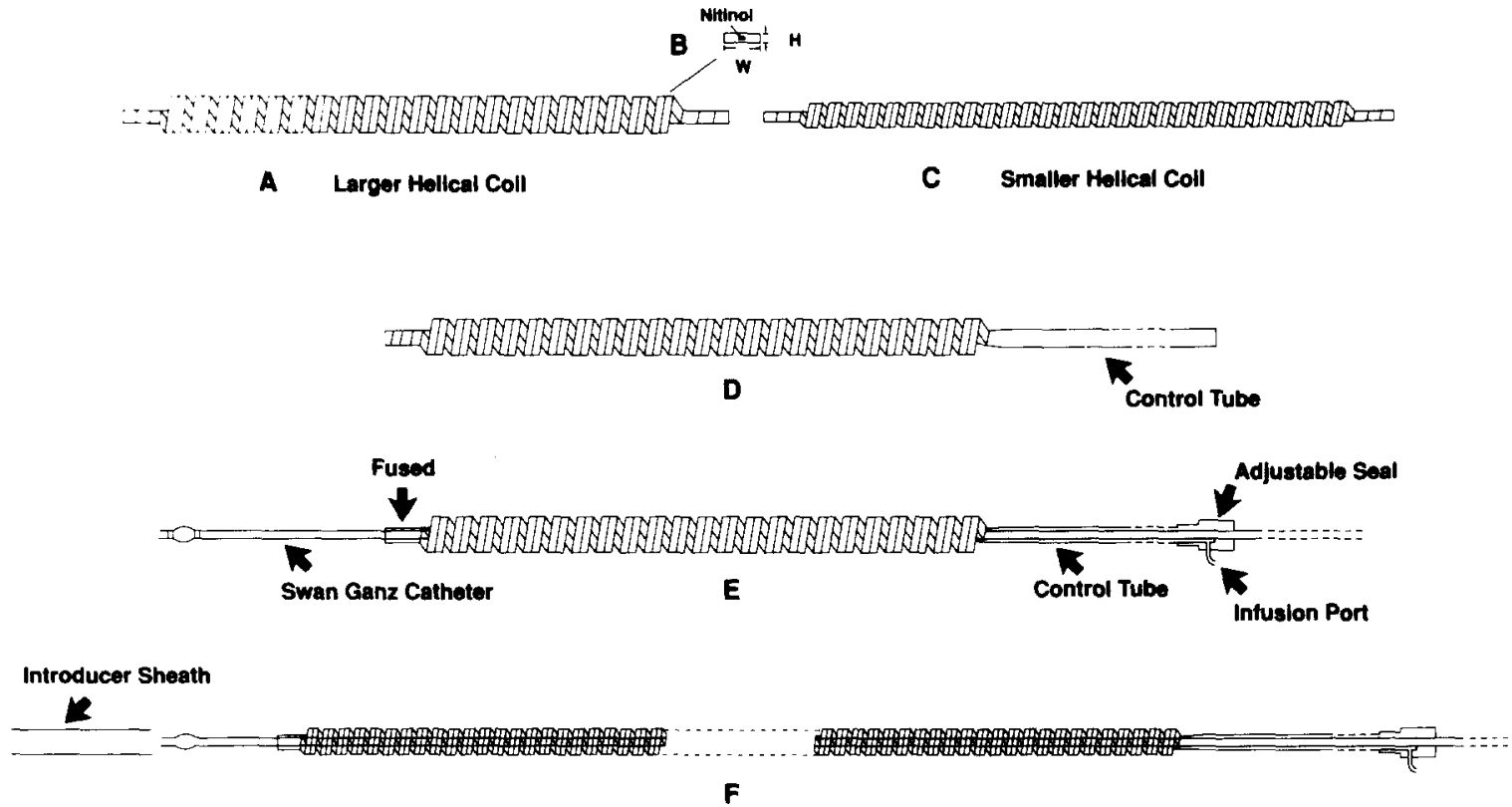

F

Helical coll mounted onto Swan Ganz

catheter, In colled postion, resdy for Insertion.

Fig. 1. A, Larger helical coil, not mounted. B, Cross-section of helical coil. C, Smaller helical coil, not mounted. D, Helical coil with added control tube. E, Turning control tube decreases or increases diameter of helical coil. Linear pull or push of control tube renders pitch of the coil smaller or greater. F, Helical coil with added control tube, mounted onto Swan-Ganz catheter, coiled up and ready for insertion through introducer sheath.

capable of inducing various degrees of decompression of the left side of the heart. Our design allows the percutaneous placement of the coil through a small, peel-away introducer system.

Helical coils are fabricated of Hytrel elastomer (Du Pont, Wilmington, Del.) and superelastic nickel-titanium (nitinol) alloy. Flat nitinol wire $(0.1 \times 0.5 \mathrm{~mm}$; (Fort Wayne Metals, Fort Wayne, Ind.) is wound around an aluminum mandrel of a desired diameter (such as 5 to 10 $\mathrm{mm}$ ) at a desired pitch (for example 2 coils $/ \mathrm{cm}$ ) and heat set at $480^{\circ} \mathrm{C}$ for 10 minutes. The coil thus formed is fused between two flat sheets of $0.125 \mathrm{~mm}$ Hytrel elastomer and trimmed to a width of 6 to $8 \mathrm{~mm}$. The resulting helical coil (Fig. $1, A$ ) is relieved of internal stress by brief immersion in a silicone oil bath at $210^{\circ} \mathrm{C}$ while wound onto the same mandrel used in the initial forming of the nitinol spring and is bonded to a section of thin-walled Hytrel elastomer tubing with an internal diameter slightly larger than the outside diameter of the flow-directed catheter on which it is to be mounted (control tube, Fig. 1,D). Finally, the control tube and the helical spring are passed over a flow-directed Swan-Ganz catheter (Baxter Healthcare Corp., Edwards Div., Irvine, Calif.), and the proximal end is firmly affixed approximately 5 to $8 \mathrm{~cm}$ from the inflation balloon (Fig. 1, $E$ ). For ease of insertion, we also mount to the Swan-Ganz catheter a lock (adjustable seal) to keep the spring in a fully coiled, partially uncoiled, or fully uncoiled position, according to need, and means to flush the space between the control tube and the Swan-Ganz catheter (Fig. 1,E). All blood-contacting surfaces are heparinized with a TDMAC-heparin complex. For the study, helical coils were produced in various sizes and lengths, ranging from 5 to $10 \mathrm{~mm}$ in internal diameter (when fully uncoiled) and varying in length (in the fully uncoiled position) from 10 to $14 \mathrm{~cm}$. All of those coils could be readily uncoiled further to an internal diameter of $15 \mathrm{~mm}$ or more.

Preliminary studies were conducted in three adult sheep weighing 40 to $50 \mathrm{~kg}$. All animal studies were approved by the Animal Care Committee of the National Heart, Lung, and Blood Institute. With the animal under general anesthesia and paralyzed, we introduced into the right external jugular vein a $14 \mathrm{~F}$ peel-away introducer (Cook Critical Care, Inc., Bloomington, Del.) under fluoroscopic guidance. Through the introducer, we passed a 7F flow-directed Swan-Ganz catheter with the helical coil in the fully coiled position (Fig. 2). After it was wedged in the pulmonary artery, the control tube was progressively uncoiled and advanced at the same time to keep the pulmonary artery valve and tricuspid valves partially or totally open (Fig. 3). To withdraw the catheter, these steps were repeated in reverse order; the control tube was turned in the opposite direction to decrease the diameter of the helical coil while being progressively withdrawn. When the helical coil had returned to its fully coiled position, the entire catheter with the coil could be easily withdrawn.

Coils so fabricated and kept in the fully coiled position were easily passed through a $14 \mathrm{~F}$ introducer sheath. Once in position, coils readily uncoiled to the original design diameter or larger (in comparison, to pass an uncoiled 8 

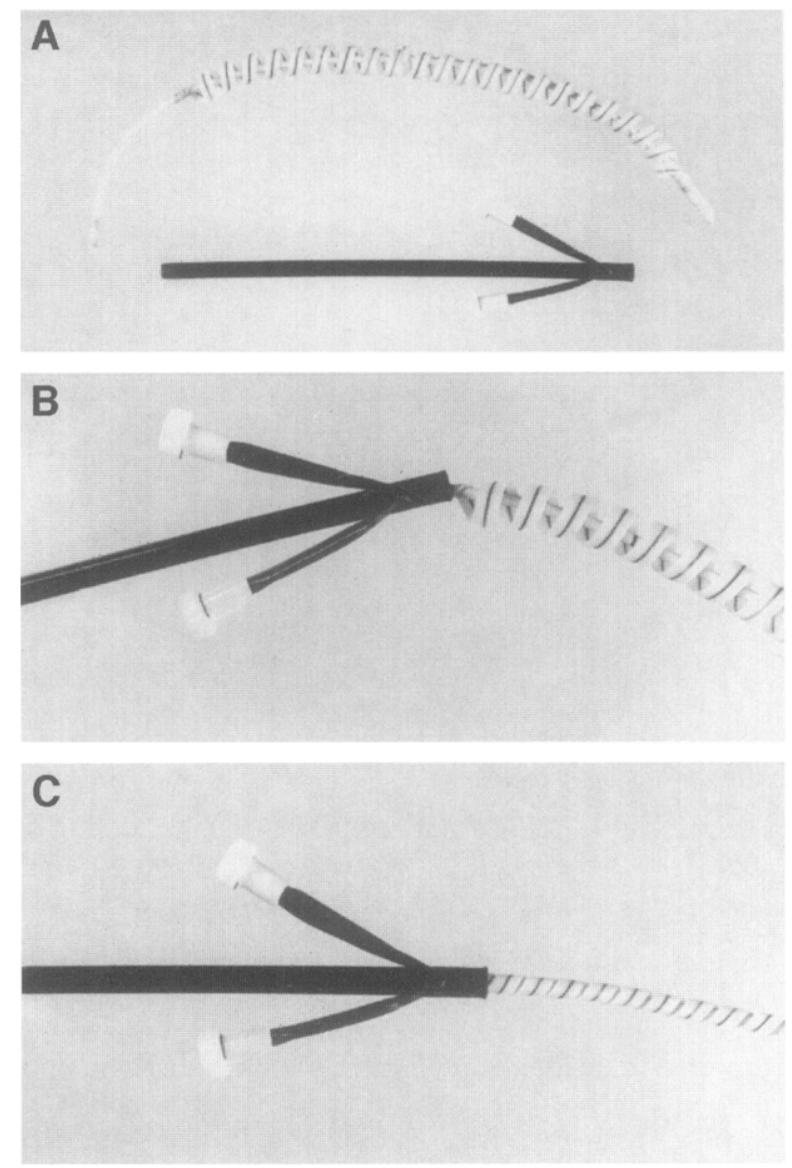

Fig. 2. A, Helical coil (expanded) and separate $14 \mathrm{~F}$ peelaway introducer. $\mathbf{B}$, Helical coil in expanded form, ready to be coiled for passage through $14 \mathrm{~F}$ introducer. $\mathrm{C}$, Helical coil in coiled form, ready for passage through $14 \mathrm{~F}$ introducer.

mm helical coil percutaneously would require a $24 \mathrm{~F}$ to 26F introducer sheath). The passage was smooth, and the nitinol reinforcement wire was readily visible under fluoroscopic guidance (Fig. 3). Once in position, uncoiling could proceed without fluoroscopic monitoring according to observation of markers placed on the control tube and the Swan-Ganz catheter and counting of the number of turns needed to partially or totally unwind the helical coil as desired. We then repeated the placement and retrieved the helical coils several times in each sheep. At the end of the studies, the animals were killed.

This innovation overcomes the previously unsolved problems of how to insert a large helical coil to rest within the lumen of the pulmonary artery valve and the tricuspid valve, how to change the diameter of the helical coil while it is lodged within the heart to obtain the desired degree of valvular insufficiency, and how to readily retrieve the helical coil when it is no longer needed.

Our previous work ${ }^{1}$ and current ongoing work with a model of partial or total cardiac failure from warm myocardial ischemia show that closed-chest partial and total cardiopulmonary bypass (demand cardiopulmonary

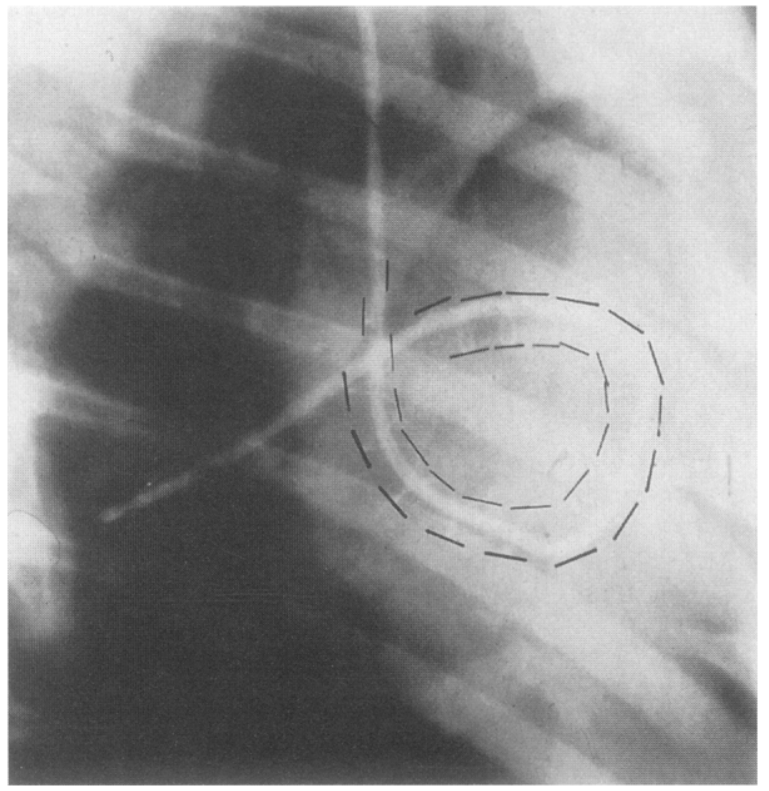

Fig. 3. Chest radiograph shows location of uncoiled helical coil in sheep (dashed lines represent radiolucent plastic components of helical coil).

bypass) can be conducted despite the most severe left ventricular failure, including ventricular fibrillation, when the left ventricle is decompressed through valves of the right side of the heart that are kept partially or totally open with a helical coil. Placement of such coils has permitted us to sustain left atrial pressure within the normal range, high extracorporeal blood flow, and high systemic arterial pressure without relying on pharmacologic agents or counterpulsation. The integrity of lung function, and the optimal conditions for myocardial recovery of whatever cause, are thus greatly enhanced.

We believe that long-term demand cardiopulmonary bypass with percutaneous decompression of the left side of the heart is well within the capabilities of extracorporeal membrane oxygenation (ECMO) for acute respiratory failure because perfusion lasting for weeks or even months is already common. This method of cardiac assistance is hence well within the realm of practicality, because any recovery of myocardial function is likely to occur within the first 5 days of ventricular assistance. ${ }^{2}$ This method may find acceptance where more conservative methods, such as counterpulsation and systemic vasodilators or other pharmacologic agents, are deemed no longer effective and when consideration is given to the implantation of a ventricular-assist device.

\section{REFERENCES}

1. Rossi F, Kolobow T, Foti G, Borelli M, Mandava S. Long-term cardiopulmonary bypass by peripheral cannulation in a model of total heart failure. J Thorac Cardiovasc Surg 1990;100:914-20.

2. Pae WE, Miller CA, Matthews Y, Pierce WS, Ventricular assist devices for postcardiotomy cardiogenic shock: a combined registry experience. J Thorac Cardiovasc Surg 1992;104: $541-53$. 